\title{
Smoking in correctional facilities: a survey of employees
}

\author{
Matthew J Carpenter, John R Hughes, Laura J Solomon, Thomas A Powell
}

\begin{abstract}
Objective-To assess level of endorsement and expected consequences of worksite smoking restriction policies among correctional employees.

Design-Mailed survey to Vermont state correctional employees.

Main outcome measures-Support for various policy alternatives for both staff and inmate smoking; expected consequences of restrictive smoking policies and smoking behaviour.
\end{abstract}

Participants-321 of $640 \quad(50 \%)$ state correctional employees responded.

Results-Employees were somewhat receptive to smoking restrictions for inmates, but less supportive of staff smoking restrictions. A complete ban on inmate smoking both indoors and outdoors was supported by $56 \%$ and $49 \%$ of never and ex-smokers, respectively, but only $15 \%$ of current smokers $(p<0.01)$. A similar ban on employee smoking was supported by $38 \%$ of never and ex-smokers, but only $3 \%$ of current smokers $(p<0.01)$. Overall, employees were most supportive $(52 \%)$ of a policy for themselves that banned indoor smoking and restricted it to certain areas outdoors. Current smokers were more likely to expect negative consequences as a result of further restrictions than were never or ex-smokers.

Conclusions-Although our findings are limited by a low response rate, most employees support an indoor ban, but not a total ban on smoking. Employees generally favoured a policy that was slightly more restrictive than the current policy, but were less supportive of tighter smoking restrictions for themselves. However, a more restrictive smoking policy is likely to result in some degree of resistance among current smoking employees, who may require specific attention to address their opposition.

(Tobacco Control 2001;10:38-42)

Keywords: smoking restrictions; policy; environmental tobacco smoke; correctional facilities

Exposure to environmental tobacco smoke (ETS) has long been identified as a health risk, both within the home ${ }^{1}$ and the worksite. ${ }^{23}$ As a result, there has been a proliferation of restrictive indoor smoking policies in the USA in the past decade. ${ }^{4}$ Currently, about $85 \%$ of US worksites have some form of a smoking restriction policy (SK Hammond, KM Emmons, unpublished data). Policies that restrict smoking indoors not only decrease exposure to ETS, ${ }^{6}$ but also reduce cigarette consumption ${ }^{7}$ and increase desire to quit ${ }^{8}$ as well as actual smoking cessation..$^{9} 10$ In most hospital and worksite settings, the majority of employees, including smokers, approve of some smoking restrictions, ${ }^{11} 12$ although current smokers are less supportive even in these settings. ${ }^{13}$

However, not all worksites are keen to impose smoking restrictions. Long term residential care facilities, especially psychiatric and correctional institutions, have been more resistant to restrictions on smoking. ${ }^{14}$ While the Joint Commission on Accreditation of Healthcare Organizations (JCAHO) mandates smoking policies for psychiatric and residential hospitals, ${ }^{15}$ comparable standards are not required by either the American Correctional Association (ACA) or the National Commission on Correctional Healthcare (NCCHC). These organisations offer recommendations for non-smoking policies but do not enforce these guidelines. ${ }^{16}$ In a national survey of over 900 correctional facilities, $45 \%$ of institutions allowed some form of smoking, either by staff or inmates. In fact, unlike hospitals and most worksites, the rate at which prisons are adopting new smoking bans has declined in recent years. ${ }^{17}$ Furthermore, exactly what restrictions are being implemented is unclear. Unfortunately, the previously published research on smoking restrictions in correctional facilities does not state whether different policies exist for inmates versus employees, or indoor versus outdoor policies. ${ }^{17-20}$

The threat of ETS is especially potent in prison settings for several reasons. First, estimates of smoking prevalence among prisoners in the USA range from $60-80 \% .{ }^{16}{ }^{21}$ Secondly, poor ventilation systems along with inadequate enforcement of existing smoking restrictions may lead to very high levels of ETS. For example, ambient air nicotine levels taken before implementation of a smoking ban in Vermont prisons averaged $6 \mu \mathrm{g} / \mathrm{m}^{3}$, with even higher levels found in common rooms and cell areas (SK Hammond, KM Emmons, unpublished data). These levels were 10 times above the $0.75 \mu \mathrm{g} / \mathrm{m}^{3}$ level that has been suggested as an acceptable level of ETS. ${ }^{22}$ Finally, the prison environment creates almost constant involuntary exposure to ETS because inmates spend the vast majority of time indoors.

ETS creates not only public health but also legal problems for jails as well. Inmates and staff complain of hazardous exposure to ETS, and in revised form

28 June 2000

Accepted 28 July 2000 
while at the same time prison administrators are reluctant to ban smoking completely because of fears of increased tension among inmates and staff. In a landmark case, the US supreme court held that inmates have a constitutional right to be free from unreasonable risks associated with ETS. ${ }^{23}$

In 1992, the state of Vermont completely banned smoking indoors and outdoors for both staff and inmates of all correctional facilities, and ETS levels dropped by as much as $80 \%$ following implementation of this policy (SK Hammond, KM Emmons, unpublished data). Because of the creation of a black market for cigarettes and the perception of increased staff-inmate tension, the policy was amended to prohibit indoor smoking but to allow smoking outdoors by staff and inmates. This policy has not been fully enforced. Smoking in individual cells and common areas remains a problem and prisoners still retain smoking paraphernalia inside the facilities. In 1996, an inmate with emphysema sued the state of Vermont claiming he was wrongfully exposed to ETS. ${ }^{24}$ A superior court subsequently found in favour of the inmate and noted that the state must protect the health needs of the inmates. The state of Vermont then asked us to examine and refine the current smoking policy for its jails and prisons.

While there is general information on tobacco restrictions in correctional facilities, ${ }^{16}{ }^{17}$ there is little information on what specific smoking restriction policies will work and how they can be adequately enforced. It has been suggested that when there is resistance to smoking policy changes, it typically comes from prison employees more than from inmates. ${ }^{16}{ }^{25}$ Smoking restrictions in non-prison worksites are typically accepted, even among smokers (50-60\%). ${ }^{26}{ }^{27}$ However, the acceptability of smoking restrictions in correctional settings is largely unknown. In the only study of employees in a prison setting, only $44 \%$ of Australian correctional employees favoured a complete ban on smoking and smokers advocated for less restrictive options than non-smokers. ${ }^{19}{ }^{20}$ Given that employee support is thought to be crucial for implementation of smoking restrictions, ${ }^{28}$ we sought to first determine correctional employees' support for various policy alternatives and to investigate their expectations regarding the consequences of further smoking restrictions in the worksite.

\section{Methods}

At the time of this survey, the Vermont Department of Corrections (DOC) employed approximately 800 staff. The present study surveyed the 640 employees who worked in one of the three prisons, the five jails, or the administrative office. Prisons are generally for those inmates who have committed more serious crimes and have extended sentences. Jails are for those held in pre-adjudication detention or those with shorter terms. We created a brief questionnaire based on previous research on smoking restrictions in hospitals and prisons. ${ }^{16} 171920$
Several policy alternatives were offered for both staff and inmate smoking, and respondents indicated their degree of support for each using a five point Likert scale ( $1=$ definitely would not support, $5=$ definitely would support). These policies ranged from the least restrictive (smoking permitted indoors and outdoors) to most restrictive (complete ban on smoking on the grounds). The policies were listed such that an employee could support more than one; therefore, low support for a policy could reflect a wish for tighter or looser restrictions. Seventeen questions assessed employee beliefs about positive and negative consequences of smoking restrictions (for example, health outcomes, rule violations). These items were also presented in a five point Likert format ( $1=$ strongly disagree, $5=$ strongly agree). Additionally, three questions assessed perceptions of the difficulty of implementing smoking restrictions. We also asked employees to indicate their smoking status, and for current smokers, cigarettes smoked per day, age of first use, and intention to quit in the next six months. We did not include demographic questions because some of the employees were concerned that they could be identified by such items.

We assigned all employees a confidential ID number, and sent the questionnaires, with self addressed stamped envelopes, to employee homes. We offered a lottery of 16 cash incentives ranging from $\$ 10$ to $\$ 100$ to those who completed the survey, and conducted a second mailing for those who did not initially respond. This study was approved by the University of Vermont Committee on Human Research.

Following the survey, we conducted five focus groups (three prisons, two jails) to discuss smoking policy in further detail. Specific officers (smokers and non-smokers alike) were invited to participate based upon their superintendent's belief that they would provide meaningful input to the discussion of smoking restrictions. We included only officers in these discussions because they are on the front line of policy enforcement. A total of 23 officers agreed to participate in the focus groups. Each group met once for approximately 75 minutes. The structure of each group was loosely framed around issues of policy enforcement and implementation, although the moderator of the groups (MJC) allowed the discussion to turn to other issues that the officers believed to be relevant.

\section{Results}

A total of 321 questionnaires were completed for a $50 \%$ response rate. Seventy eight $(24 \%)$ of the respondents were current smokers, 120 $(38 \%)$ were ex-smokers, and $121(38 \%)$ were never smokers. Two employees did not indicate their smoking status. The mean (SD) age of first daily cigarette smoking among current smokers was 17.7 (4.8) years. Smokers smoked an average of less than a pack of cigarettes per day (17.9 (8.3)); $41 \%$ of daily cigarettes were smoked while at work. Most smokers (70\%) 
Table 1 Support for inmate and employee smoking policies by type of employment (alternatives are independent of each other)

\begin{tabular}{llll}
\hline & \multicolumn{2}{l}{ Per cent support } & \\
\cline { 2 - 4 } & $\begin{array}{l}\text { Uniformed } \\
\text { employees }(n=202)\end{array}$ & $\begin{array}{l}\text { Non-uniformed } \\
\text { employees }(n=112)\end{array}$ & $p$ Value \\
\hline Inmate policies & & & \\
$\quad$ No restrictions at all & 9 & 22 & - \\
Limited indoors, permitted outdoors & 40 & 46 & $<0.01$ \\
Banned indoors, permitted outdoors & 60 & 68 & - \\
Banned indoors, limited outdoors & 59 & 47 & - \\
Banned indoors and outdoors & 41 & & $<0.05$ \\
Employee policies & & 8 & $<0.05$ \\
$\quad$ No restrictions at all & 14 & 21 & $<0.05$ \\
Limited indoors, permitted outdoors & 40 & 32 & \\
$\quad$ Banned indoors, permitted outdoors & 46 & 59 & \\
Banned indoors, limited outdoors & 47 & 38 & \\
Banned indoors and outdoors & 25 & & \\
\hline
\end{tabular}

Seven employees did not indicate their position.

Table 2 Support for inmate and employee smoking policies by employee smoking status, after controlling for employee position (alternatives are independent of each other)

\begin{tabular}{|c|c|c|c|c|}
\hline & \multicolumn{4}{|l|}{ Per cent support } \\
\hline & $\begin{array}{l}\text { Never smokers } \\
(n=121)\end{array}$ & $\begin{array}{l}\text { Ex-smokers } \\
(n=120)\end{array}$ & $\begin{array}{l}\text { Current smokers } \\
(n=78)\end{array}$ & $p$ Value \\
\hline \multicolumn{5}{|l|}{ Inmate policies } \\
\hline No restrictions at all & 5 & 8 & 14 & - \\
\hline Limited indoors, permitted outdoors & 13 & 30 & 69 & $<0.001^{\star}$ \\
\hline Banned indoors, permitted outdoors & 55 & 46 & 69 & $<0.02 \dagger$ \\
\hline Banned indoors, limited outdoors & 68 & 60 & 60 & - \\
\hline Banned indoors and outdoors & 56 & 49 & 15 & $<0.001 \neq$ \\
\hline \multicolumn{5}{|l|}{ Employee policies } \\
\hline No restrictions at all & 8 & 6 & 28 & $<0.001 \ddagger$ \\
\hline Limited indoors, permitted outdoors & 22 & 22 & 67 & $<0.001 \neq$ \\
\hline Banned indoors, permitted outdoors & 35 & 36 & 57 & $<0.02 \ddagger$ \\
\hline Banned indoors, limited outdoors & 58 & 55 & 36 & $<0.02 \ddagger$ \\
\hline Banned indoors and outdoors & 39 & 38 & 3 & $<0.001 \neq$ \\
\hline
\end{tabular}

^Post-hoc comparisons: current smokers $>$ ex-smokers $>$ never smokers.

†Post-hoc comparisons: current smokers $>$ ex-smokers.

$\ddagger$ Post-hoc comparisons: never smokers and ex-smokers $>$ current smokers.

Table 3 Beliefs about smoking restrictions

\begin{tabular}{|c|c|c|c|}
\hline & \multicolumn{3}{|c|}{ Per cent agree } \\
\hline & $\begin{array}{l}\text { Never } \\
\text { smokers } \\
(n=121)\end{array}$ & $\begin{array}{l}\text { Ex-smokers } \\
(n=120)\end{array}$ & $\begin{array}{l}\text { Current } \\
\text { smokers } \\
(n=78)\end{array}$ \\
\hline \multicolumn{4}{|l|}{ Negative consequences of restrictions } \\
\hline $\begin{array}{l}\text { Further restrictions would result in unrest and violence from } \\
\text { smoking inmates }\end{array}$ & 50 & 48 & 82 \\
\hline The smoking policy at my facility is too restrictive & 8 & 9 & 29 \\
\hline Further restrictions would hurt quality of work & 19 & 18 & 53 \\
\hline Further restrictions on inmate smoking violates civil liberties & 7 & 16 & 36 \\
\hline Further restrictions on staff smoking violates civil liberties & 17 & 18 & 56 \\
\hline $\begin{array}{l}\text { Cigarettes are a useful way to reward good behaviour among } \\
\text { inmates; ban on smoking would eliminate this reinforcement }\end{array}$ & 15 & 19 & 45 \\
\hline $\begin{array}{l}\text { Further restrictions on staff smoking would decrease morale } \\
\text { and production at work }\end{array}$ & 22 & 26 & 49 \\
\hline $\begin{array}{l}\text { Further restrictions on smoking would result in an increase in } \\
\text { rule violations unrelated to smoking }\end{array}$ & 46 & 38 & 65 \\
\hline $\begin{array}{l}\text { Further restrictions on smoking would result in increased } \\
\text { tension between inmates and staff }\end{array}$ & 58 & 55 & 83 \\
\hline Positive consequences of restrictions & & & \\
\hline $\begin{array}{l}\text { Further restrictions on smoking would be okay if help were } \\
\text { offered to those who want to quit }\end{array}$ & 67 & 63 & 66 \\
\hline $\begin{array}{l}\text { Further restrictions on smoking would increase the chance that } \\
\text { employees would try to quit smoking }\end{array}$ & 43 & 59 & 46 \\
\hline $\begin{array}{l}\text { Further restrictions on smoking would increase the chance that } \\
\text { inmates would try to quit smoking }\end{array}$ & 56 & 53 & 35 \\
\hline $\begin{array}{l}\text { Further restrictions on smoking would be okay if nicotine } \\
\text { substitutes (e.g. the "patch") were offered during work hours }\end{array}$ & 36 & 50 & 49 \\
\hline
\end{tabular}

had at least some desire to stop smoking, and the majority ( $52 \%)$ reported they "possibly" intended to quit in the next six months.

Responses were initially compared by type of facility (jail $v$ prison) and employee position (uniformed employees $v$ non-uniformed employees). For clarity, responses to Likert items were collapsed to indicate support ("probably would support" and "definitely would support") and $\chi^{2}$ analyses were conducted. Support for inmate and employee smoking policies generally did not differ as a function of type of facility. Uniformed employees, who included correctional officers and shift supervisors, supported less restrictions than did non-uniformed employees (table 1).

Because responses differed by position, further analysis of smoking policies controlled for employee position via analysis of covariances (ANCOVAs) (table 2). In general, employees favoured some restrictions for inmates, but were less supportive of such policies for themselves. In terms of inmate smoking, $56 \%$ of never smokers and $49 \%$ of ex-smokers supported a complete ban indoors and outdoors, while only $15 \%$ of current smokers supported this option $(p<0.001)$. There was, however, some common ground for an inmate smoking policy. Employees indicated a moderate amount of support (over $60 \%$ ) for a complete ban indoors and limited smoking outdoors for inmates.

In terms of employee smoking, never and ex-smokers were concordant, but current smokers favoured decidedly less restrictive options. The most comprehensive option, a total ban on employee smoking indoors and outdoors, received support from approximately $38 \%$ of never and ex-smokers and only 3\% of current smokers $(p<0.001)$. The next most restrictive option for employee smoking, a complete ban indoors and limited outdoor smoking, received support from approximately $57 \%$ of never and ex-smokers, but only $36 \%$ of current smokers $(\mathrm{p}<0.02)$.

A similar pattern occurred with general beliefs about the consequences of further smoking restrictions in the worksite (table 3). More current smokers anticipated negative consequences of further smoking restrictions than did never or ex-smokers. With two exceptions, over $45 \%$ of current smokers anticipated negative outcomes in morale, quality of work, tension between staff and inmates, other rule violations, and unrest by inmates. In contrast, with one exception, less than half of never and ex-smokers expected these negative consequences. On a positive note, approximately two thirds of all respondents agreed that further restrictions would be acceptable if help were offered to those who wanted to quit smoking.

Rather than conduct multiple comparisons for each of the beliefs regarding consequences of restrictions, a factor analysis was conducted for all items. This resulted in a two factor solution; one factor reflected the negative consequences of restrictions (Cronbach $\alpha=0.87$ ), while the other factor reflected the positive benefits (Cronbach $\alpha=0.71$ ) (table 3). After controlling for employee position, only endorsement of the negative consequence factor significantly differed across smoking groups $\left(F_{2}{ }_{319}=43.8, \mathrm{p}<0.001\right)$. Post hoc (Bonferroni) comparisons indicated that negative beliefs about smoking restrictions were endorsed significantly more by current smokers than by never or ex-smokers. There 
was also a main effect for type of facility on negative beliefs $\left(F_{2}{ }_{302}=3.9, \mathrm{p}=0.02\right)$, such that prison employees believed more negative consequences would result than did jail employees. Finally, we observed a significant interaction between correctional facility and smoking on beliefs about negative outcomes of further smoking restrictions $\left(F_{16}{ }_{284}=1.7\right.$, $\mathrm{p}<0.05)$. At all facilities, current smokers expected more negative consequences than did never or ex-smokers, but whether ex-smokers expected more negative consequences than did never smokers varied across sites.

Current smokers differed from never and ex-smokers in their beliefs about the difficulty of implementing more restrictive smoking policies. Among current smokers, $46 \%$ believed that further restrictions would be very difficult to institute, and $59 \%$ believed that problems would persist. In contrast, only $23 \%$ of both never and ex-smokers believed that restrictions would be very difficult to implement and few $(30 \%)$ believed that problems would be long lasting.

Qualitative information derived from the focus groups indicated that officers generally believed that smoking restrictions are possible given appropriate and consistent enforcement. Officers noted the necessity of both standardised disciplinary procedures and a strict penalty system as critical to the success of any smoking restriction. In addition, officers also believed that restrictions are feasible when smoking assistance is provided, both to smoking inmates and officers. Finally, the focus group participants acknowledged that smoking restrictions would result in some degree of unrest initially, but that successful implementation requires a long term commitment.

\section{Discussion}

Our findings indicate that correctional employees are generally favourable towards smoking restrictions for inmates, but are less supportive of further restrictions for themselves. The current state wide policy in Vermont correctional facilities bans indoor smoking for both inmates and staff, but does allow for outdoor smoking. Most employees agree with this policy; however, most never and ex-smokers would like to see slightly tighter controls, including restricted areas for outdoor smoking. In contrast, most current smokers generally favoured policies that were less restrictive than the existing policy, including limited indoor smoking areas for both inmates and employees, with unlimited smoking outdoors.

Beliefs regarding the potential consequences of further smoking restrictions also differed across smoking groups. Current smokers were more likely to anticipate negative outcomes for tighter smoking restrictions than were either never or ex-smokers. Examples of these negative outcomes included beliefs that further restrictions would result in increased tension between staff and inmates and an increase in other rule violations. Current smokers believed that these negative outcomes would be more severe and long lasting than did never and ex-smokers.

A limitation of this study was the $50 \%$ response rate. Twenty four per cent of respondents were current smokers. We suspect the actual prevalence of smoking in correctional employees is higher. We could not find data on the prevalence of smoking either in state of Vermont correctional employees or in prior published reports of other correctional systems. To ensure confidentiality and thereby increase response rates, we purposely omitted demographic questions. Unfortunately, this prevents us from estimating any response bias. If, as we suspect, we undersampled smokers, then our results may overestimate support for restrictions.

The only other study to assess support of smoking restrictions among correctional employees was conducted in Australian correctional facilities. ${ }^{19}{ }^{20}$ Unfortunately, these researchers did not distinguish whether their results applied to inmate smoking, employee smoking, or both. In that study, $15 \%$ of 225 employees favoured a complete smoking ban, and $44 \%$ of the workers favoured a ban in all indoor areas. Non-smokers favoured tighter restrictions than did smokers.

Our results suggest that specific interventions may be necessary to build acceptance among employees who currently smoke. Such interventions may include providing a clear rationale for restrictive smoking policies (for example, to prevent ETS), dispelling paranoia (for example, the policy is not meant to force employees to stop smoking), and citing legal precedents (for example, there is no "right to smoke"). In light of health and legal concerns, smoking policies in correctional facilities need to be evaluated. Although anecdotal reports suggest that there are few problems among prisons and jails that do impose smoking restrictions, ${ }^{25}$ empirical research on this is lacking. The current study, using both survey and focus group data, suggests a moderate degree of smoking restrictions is not only supported, but feasible as well.

This study was funded by NIDA training grant DA-07242 (MJC), a Career Development Award, DA-00109 (JRH), and grant DA11557 from the National Institute on Drug Abuse. The authors would like to thank Jonathan Hirsch and Ashley Bryant for their assistance.

1 Emmons KM, Hammond SK, Abrams DB. Smoking at home: the impact of smoking cessation on nonsmokers exposure to environmental tobacco smoke. Health Psychol 1994;13:516-20.

2 Emmonds KM, Abrams DB, Marshall RJ, et al. Exposure to environmental tobacco smoke in naturalistic settings. Am $\mathcal{F}$ Public Health 1992;82:24-8.

3 Barad CB. Smoking on the job: the controversy heats up. Occup Health Saf 1979;48:21-4.

4 Fielding JE. Banning worksite smoking. Am f Public Health 1986;76:957-9.

5 Ying JYC, Abernathy T, Choi BCK. A comprehensive evaluation of the 1993 city of Toronto smoking by-laws. Revue Canadienne De Sante Publique 1994;86:32-6.

6 Marcus BH, Emmons KM, Abrams DB, et al. Restrictive workplace smoking policies: impact on nonsmokers' tobacco exposure. F Public Health Policy 1992;13:42-51.

7 Pezzino G, Remmington, PL, Anderson $\mathrm{H}$, et al. Impact of a smoke-free policy on prisoners in Wisconsin, United States. Tobacco Control 1992;1:180-4.

8 Wakefield MA, Wilson D, Owen $\mathrm{N}$, et al. Workplace smoking restrictions, occupational status, and reduced cigarette consumption. $\mathcal{F}$ Occup Med 1992;34:693-7. 
9 Glasgow RE, Cummings KM, Hyland A. Relationship of worksite smoking policy to changes in employee tobacco use: finding $44-8$.

10 Sorsensen G, Rigotti N, Rosen A, et al. Effects of a worksite nonsmoking policy: evidence for increased cessation. $A m \mathcal{F}$ Public Health 1991;81:202-4.

11 Pederson LL, Bull SB, Ashley MJ. Smoking in the workplace: do smoking patterns and attitudes reflect the legislative environment? Tobacco Control 1996;5:39-45.

12 Borland R, Owen N, Hill D, et al. Changes in acceptance of workplace smoking bans following their implementation: a prospective study. Prev Med 1990;19:314-22.

13 Stillman FA, Hantula DA, Swank R. Creating a smoke-free hospital: attitudes and smoking behaviors of nurses and physicians. American fournal of Health Promotion 1994 physicians.

14 Skolnick A. While some correctional facilities go smokefree, others appear to help inmates to light up. $\mathscr{F} A M A$

15 US Joint Commission on Accreditation of Healthcare Organizations. Accreditation manual for hospitals. Oakbrook Terrace, Illinois: Joint Commission on Accreditation of

16 Vaughn MS, del Carmen RV. Research note: smoking in prisons-a national survey of correctional administrators in the United States. Crime \& Delinquency 1993;39:225-39.

17 Falkin GP, Strauss SM, Lankenau SE. Cigarette smoking policies in American jails. American fails 1998;8:9-14.

18 Centers for Disease Control. Cigarette smoking bans in county jails-Wisconsin, 1991. MMWR Morb Mortal Wkly Rep 1992;41:100-3.
19 Wares H, Biggins D. Developing policy for a smoke-free work environment in a prison. Part $1 \mathrm{~A}$ survey on smoking and its control. Fournal of Occupational Health Safety 1993; 9:315-23.

20 Biggins D, Wares H. Developing policy for a smoke-free work environment in a prison. Part 2 Policy development. fournal of Occupational Health Safety 1993;9:325-30.

21 Romero CA, Connell FA. A survey of prison policies regarding smoking and tobacco. Fournal of Prison E Fail Health 1988;7:27-36.

22 Repace JL, Lowrey AH. An indoor air quality standard for ambient tobacco smoke based on carcinogenic risk. NY State F Med 1985;85:381-3.

23 Helling v. McKinney, 113 S. Ct. 2475, 1993.

24 Gardner v. Gorcyzk, No. S542-10-95 Wncv, Superior Court of Washington County, VT May 29, 1996.

25 Vaughn MS, del Carmen RV. Legal and policy issues from the supreme court's decision on smoking in prisons. Federal Probation 1993;57:34-9.

26 Dixon RD, Lowery RC, Levy DE, et al. Self-interest and public opinion toward smoking policies: a replication and extension. Public Opinion Quarterly 1991;55:241-54.

27 Biener L, Abrams D, Emmonds KM, et al. Evaluating worksite smoking policies: methodologic issues. $N Y$ State $\mathcal{F}$ Med 1989;89:5-10

28 Goldsmith JR, Hurt RD, Slade J. Development of smoke-free chemical dependency units. F Addict Dis 1991; 11:67-77.

\section{Electronic pages}

\section{Tobacco use around the globe}

Tobacco Control receives many submissions from authors describing the prevalence of tobacco use in different populations. As stated on our website, ${ }^{1}$ we give low priority to such papers, particularly if they describe very local populations. This is because such studies are generally of low interest to an international readership most interested in papers with universal policy relevance. However, we recognise that in many less developed nations, researchers have few opportunities to publish data on the local prevalence of tobacco use. Accordingly, from this issue we have introduced a section called "Tobacco use around the globe" which will feature abstracts of papers in the print version of the journal and full text through $e \mathrm{TC}$.

1 http://tc.bmjjournals.com/misc/ifora.shtml?ck=nck

\section{Prevalence and correlates of smoking on the roof of the world}

Syed MA Shah, Ahmed A Arif, George L Delclos, Asif $R$

Khan, $A$ Khan

Objective-To determine the prevalence and correlates of cigarette smoking among adults in high mountain rural areas of northern Pakistan.

Design-Cross sectional survey.

Participants-A sample of 4203 adults (aged 18 years and over) were selected by stratified random sampling from 16 villages.
Main outcome measure-Self reported smoking prevalence; age of smoking initiation; daily cigarette consumption and association between current smoking and sociodemographic variables, use of snuff, wine, body mass index, blood pressure, family history of stroke, and hypertension.

Results-614/1406 men (43.7\%) and 154/2797 (5.5\%) women reported smoking cigarettes. The age standardised prevalence of smoking was $40.5 \%$ for men and $6.3 \%$ for women. Men were more likely (odds ratio (OR) 6.5, 95\% confidence interval (CI) 4.75 to 8.79 ) to be smokers. Smokers were more likely to use snuff (OR 1.39, 95\% CI 1.12 to 1.73 ), drink wine (OR 3.47, 95\% CI 2.81 to 4.29 ), and were more likely to work as farmers (OR 1.55, 95\% CI 1.05 to 2.29 ) or shopkeepers (OR 2.63, 95\% CI 1.67 to 4.14). Individuals with college level education and with desirable body mass index were less likely to smoke (OR $0.55,95 \%$ CI 0.35 to 0.87 ; OR $0.74,95 \%$ CI 0.57 to $0.96)$.

Conclusion-Cigarette smoking is a major public health problem in this high mountain community of Pakistan, particularly among the male population, the majority of whom begin to smoke quite early in life. A comprehensive tobacco control effort incorporated into the existing community based health infrastructure is needed.

(Tobacco Control 2000;10:e1) www.tobaccocontrol.com/ cgi/content/full/10/1/e1 